Revista Espaço do Currículo

ISSN $1983-1579$

Doi: $10.22478 /$ ufpb.1983-1579.2018v3n11.42394

http://periodicos.ufpb.br/ojs2/index.php

\title{
EDUCAÇÃO AMBIENTAL E INTERCULTURA - pensando um currículo a partir dos trópicos
}

ENVIRONMENTAL EDUCATION AND INTERCULTURE - thinking a curriculum from the tropics

Sandra Maders ${ }^{1}$

Valdo Barcelos ${ }^{2}$

Resumo: Este artigo se refere aos resultados de pesquisa desenvolvida com financiamento/CNPq/CAPES. Entre os objetivos está o de promover a reflexão sobre as possibilidades de construção de conhecimento curricular numa perspectiva intercultural. Foram tomadas como referência as contribuições de dois pressupostos epistemológicos da obra de Humberto Maturana: a Biologia do Amor (BA) e a Biologia do Conhecimento (BC), bem como as proposições filosóficas da Antropofagia Cultural Brasileira (ACB) para a construção de uma educação ambiental (EA) a partir dos trópicos. Estas proposições estão ancoradas na ideia de que a construção do conhecimento, pode se dar via diferentes práticas didáticas, metodológicas, pedagógicas e curriculares. Neste caso estamos propondo a BA e a BC como princípios epistemológicos orientadores do processo da aprendizagem humana na busca de ruptura com a cultura de dominação de origem patriarcal. Sintetizando: (1) em contrapartida a uma organização curricular hegemonizada pela razão, propomos a BA a BC como pressupostos epistemológicos, para uma organização curricular que tenha o amor como a emoção que nos institui, como seres sociais, capazes de edificar um mundo social e ecologicamente mais justos e (2) uma EA a partir dos trópicos referenciada nos pressupostos filosóficos da $A C B$ que busca romper com a prática subalternizante de copiar e imitar modelos sem a sua devida contextualização. As atividades de EA são um momento privilegiado, tanto para ampliar nossas concepções curriculares quanto para criar, inventar alternativas que busquem romper com a prática tão antiga de copiar e de imitar ao invés de criar e inovar.

Palavras-Chave: Biologia do Amor/Biologia do conhecer. Antropofagia Cultural. Educação Ambiental. Currículo e Intercultura.
Abstract: This article refers itself to the results obtained from the research developed with the financing of CNPq/CAPES. Amongst the goals of the research is to promote a reflection about the possibilities of building a curricular knowledge from an intercultural perspective. Two epistemological assumptions were taken from Humberto Maturana's work as references: the Biology of Love (BL) and the Biology of Knowledge (BK), as well as the philosophical propositions of the Brazilian Cultural Anthropophagy (BCA) for the construction of an environmental education (EE) from the tropics. These propositions are anchored to the idea that the building of knowledge can be made through different didactical, methodological, pedagogical and curricular practices. In this case we are proposing the $\mathrm{BL}$ and the $\mathrm{BK}$ as epistemological principles, mentors of the human learning process in the search for a break with the culture of domination of a patriarchal origin. To sum up: (1) in the counterpart to a curricular organization hegemonized by reason, we propose $\mathrm{BL}$ and $\mathrm{BK}$ as epistemological assumptions, for a curricular organization that has love as our founding emotion, as human beings, as social beings, capable to build a social and ecological fairer world and (2) an EE from the tropics referenced on the BCA philosophical assumptions that longs to break with the subordinating practice of copying and imitating models without its proper contextualization. The BA activities are a privileged moment, to broaden our curricular conceptions such as to create alternatives that seek to break with the very ancient practice of copying and imitating rather than creating and innovating.

Keywords: Biology of Love/Biology of Knowledge. Cultural Anthropophagy. Environmental Education. Curriculum and Interculture.

\footnotetext{
${ }^{1}$ Professora Adjunta na Unipampa, atua no curso de Ciencias da Natureza Licenciatura. Doutora e Mestre em Educação/UFSM. Pedagoga. E-mail:<sandraufsmppge@gmail.com>

2 Professor Titular UFSM. Atua no departamento de Administração Escolar. Pesquisador 1D CNPq. E-mail: <vbarcelos@terra.com.br>
} 


\section{PRIMEIRAS PALAVRAS}

Os estudos e pesquisas no campo da construção de conhecimento sobre as diretrizes curriculares educacionais, já percorreram um extenso caminho até os dias atuais. Contudo, os desafios que ainda se apresentam continuam a exigir que aprofundemos os processos de investigação e de busca de interlocuções com diferentes áreas de produção de conhecimento e com diferentes pensadores. Uma das formas de fazermos isto é buscando interlocuções com autores e áreas de conhecimento que nos possibilitem diálogos e conversações nos espaços de interfaces com a educação. A expressão conversações utilizadas nesse texto, têm que ver com o que elas significam para Humberto Maturana ${ }^{3}$ - autor cujas ideias tem orientando nossas pesquisas em educação. Para esse autor a existência humana acontece no processo relacional do conversar. Estamos nos referindo à proposição de que nosso ser biológico, como humanos, se constrói na imersão do ato de conversar. Conversar é, nesse sentido, o entrelaçamento entre razão e emoção num processo de linguagem comum num determinado espaço de convivência e no tempo presente. Uma das condições necessárias para que essa conversa se estabeleça é, para Maturana, a necessidade da escuta ${ }^{4}$ do outro. Esta escuta precisa dar-se levando em consideração o entrelaçamento das emoções e das atitudes deste outro no fluir do seu viver cotidiano. Este artigo se refere aos resultados de uma pesquisa que conta com financiamento do CNPq/CAPES e apoio institucional da Universidade Federal de Santa Maria. Entre os principais objetivos desta pesquisa e das atividades de formação continuada de professores (as) está o de promover a reflexão sobre as possibilidades de construção de conhecimento curricular numa perspectiva intercultural. Para este trabalho serão referências as contribuições de dois pressupostos epistemológicos e científicos na obra de Maturana, quais sejam: a Biologia do Amor (BA) e a Biologia do Conhecimento (BC)5, bem como as proposições filosóficas da Antropofagia Cultural Brasileira (ACB) para a construção de uma educação ambiental (EA) a partir dos trópicos. Estas duas proposições estão ancoradas na ideia de que a construção do conhecimento, bem como o processo de aprendizagem humana pode se dar via diferentes metodologias, didáticas, pedagogias e alternativas curriculares. Outro ponto importante e que deve ser levado em consideração é que não existe uma separação entre aquilo que as epistemologias tradicionais chamam de dimensão biológica e dimensão cultural da pessoa e, consequentemente, nos seus processos de viver. Entre estes processos está à produção de conhecimento. Para Maturana (1995; 2001; 2004) o que existe é um entrelaçamento permanente e recorrente entre essas duas dimensões (cultura e biologia) que nos constituem como humanos.

Neste caso estamos propondo nos basearmos na BA e na BC como princípios epistemológicos orientadores do processo da aprendizagem humana em busca de uma ruptura com a cultura da dominação de origem patriarcal. Um dos pontos de partida desta proposição é de que nos construímos humanos não pela competição, mas, sim, pela cooperação. Sintetizando: em contrapartida a uma organização curricular hegemonizada pela na razão, propomos a BA a BC como pressupostos epistemológicos para uma

\footnotetext{
${ }^{3}$ Pensador chileno começou a estudar medicina em 1948 na Escola de Medicina da Universidade do Chile. Continuou seus estudos na Inglaterra em 1954. PhD em biologia. (Harvard-1958). Após concluir o PhD, continuou estudando e nesse período publicou inúmeros artigos sobre a visão da rã. Através desses estudos acabou por descobrir que as operações realizadas pela retina são o que determinam o que o animal vê. E, mais do que isso, compreendeu que o viver do animal é que determina como e o quê o animal vê. Entende ele, assim, que não há determinação exterior às operações realizadas pelos organismos que determine neles o que acontece no seu operar. Ao regressar ao Chile em 1960, dedicouse a estudar via dois caminhos investigativos (1) os processos neurofisiológicos da visão em pombas e (2) estudando os sistemas vivos como sistemas autônomos. Com esses estudos elaborou suas principais ideias sobre o sistema nervoso. A sua compreensão sobre o sistema nervoso vai permitir uma abordagem nova sobre o fenômeno humano.

${ }^{4} \mathrm{~A}$ palavra escuta aqui utilizada é intencional. Com ela quero ressaltar a importância de, mais que ouvirmos o que o outro tem a dizer (seja criança, adolescente ou adulto), há que parar para lhe dar atenção. Ou seja: dar à palavra escuta seu sentido de origem: auscultare, que está relacionada a dar atenção ao que vem de dentro. Dar espaço para a voz do interior. Ouvir o e com o coração, com a emoção e não apenas com a razão.

${ }^{5}$ Biologia do amor e Biologia do conhecimento: Humberto Maturana apresenta estas denominações para especificar um espaço de reflexão. $O$ espaço de reflexão entendido como um domínio do nosso viver que se estabelece nas relações que participamos no conversar. No conversar como o entrelaçamento do emocionar e do linguajear.
}

Rev. Espaço do Currículo (online), João Pessoa, v.11, n.3, p. 325-339, set./dez. 2018. 
Doi: $10.22478 /$ ufpb.1983-1579.2018v3n11.42394

http://periodicos.ufpb.br/ojs2/index.php

organização curricular que tenha o amor como a emoção que nos institui como seres sociais, capazes de edificar um mundo social e ecologicamente mais justos.

Esta pesquisa tem demonstrado, até o momento, que a BA e a $B C$ nos possibilitam pensar, organizar e executar uma proposta educacional em geral, e uma proposição curricular em educação ambiental (EA) em particular, onde a emoção e a afetividade sejam o principal aspecto a ser levado em consideração quando nos propomos desenvolver um trabalho pedagógico que tenha como desejo e objetivo incentivar a criação de espaços de convivência escolar onde a emoção que predomine seja a emoção do amor. Com isto estaremos criando espaços de privilegiamento de algumas relações em detrimento de outras. Alguns exemplos de relações a serem privilegiadas seriam aquelas que incentivam a cooperação, a solidariedade, a empatia, a tolerância, o reconhecimento do outro, o cuidado ecológico. Já, as relações a serem evitadas seriam as que incentivam a competição, a discriminação, a intolerância, a coerção, a exclusão e a objetivação do outro.

Acreditamos que nossas atividades de EA são um momento privilegiado, tanto para ampliar nossas concepções curriculares quanto para criar, inventar alternativas que busquem romper com a prática tão antiga de copiar e de imitar ao invés de criar de inovar. Na segunda parte desse artigo apresentamos a alternativa de uma Educação Ambiental nos Trópicos tomando a Antropofagia Cultural Brasileira como uma proposição filosófica e epistemológica.

\section{EDUCAÇÃO AMBIENTAL E CURRÍCULOS}

A expressão "currículos", no plural, é intencional neste texto. Utilizamo-la levando em conta o que sugere Jane Paiva, pesquisadora de currículo no Brasil. Para a autora é importante não perder de vista que não existe apenas uma concepção curricular em andamento nas escolas, mas, sim, várias. Nas suas palavras, "O que se observa é que não há somente um currículo nas escolas, mas muitos em ação, embora se tenda a pensar que ele é único, e que se pode homogeneizá-Io" (PAIVA, 2004, p.40). Vemos, na reflexão feita pela autora, uma possibilidade de aproximação entre sua ideia de currículo, organizado como se fosse uma rede de entrelaçamento de conhecimentos, saberes e experiências, com a proposição epistemológica apresentada por Maturana no seu livro A Árvore do conhecimento. Nesta proposição, o autor alerta para a necessidade de estarmos sempre atentos para algo que, mesmo parecendo uma obviedade, não raro é esquecido. O autor adverte que "tudo o que é dito é dito por alguém" e que "todo fazer é conhecer e todo conhecer é fazer" (MATURANA, 1995, p.69). A EA é uma temática que se situa nas fronteiras entre diferentes disciplinas, áreas de conhecimentos e saberes. Nessa perspectiva, ao pensarmos um currículo em EA, há que estarmos atentos para a necessidade de um olhar ampliado e que visa relações inter e transdisciplinares.

Esta forma de pensar a ação educativa nos desafia a nunca esquecer que não há um lá fora onde se buscarão os ingredientes necessários para construção do conhecimento. Seja ele de que tipo e em que área for. Por exemplo: nas questões relacionadas à construção de alternativas curriculares. A justificativa, para esta afirmação, buscamos em Maturana, quando este diz que "A experiência de qualquer coisa "lá fora" é validada de modo especial pela estrutura humana, que torna possível "a coisa" que surge na descrição" (1995, p.68). É justamente este encadeamento entre atitudes e experiências das pessoas como seres no mundo (FREIRE, 1997) e que agem de forma inseparável daquilo que são particularmente, e aquilo que o mundo parece ser que indicam algo fundamental que não pode ser tergiversado, pois, "Todo ato de conhecer produz um mundo" (MATURANA, 1995, p.68).

Ao pensarmos alternativas de Diretrizes Curriculares em geral, e em especial para EA, há que levar em consideração esta proposição, pois, ela nos possibilitará abrir espaços para que as experiências trazidas pelos (as) educandos (as) se manifestem e, mais que isso: sejam levadas em consideração no momento de refletirmos sobre o que realmente faz sentido e tem relevância que justifique sua inclusão numa determinada configuração curricular. Esta forma de pensar as alternativas curriculares vai ao encontro do que sugere a pesquisadora de currículo Inês Barbosa de Oliveira quando propõe que é preciso compreender o currículo 
para além de mera lista de conteúdos, mas, sim, "como criação cotidiana daqueles que fazem as escolas e como prática que envolve todos os saberes e processos interativos do trabalho pedagógico realizado por alunos $e$ professores" (BARBOSA, 2004, p.09). Já para o educador ambiental Marcos Reigota existe um espaço imenso a ser ocupado na educação quando se quer pensar a sala de aula e nossas práticas educativas. São os espaços ocupados pelas narrativas das pessoas ditas "anônimas". Para Reigota (2003, p.207), a escolha por abrir oportunidades para que as vozes destes "anônimos" sejam escutadas na educação se constitui numa opção possível e, em nosso entendimento, está em acordo com uma ideia de pensar um currículo numa perspectiva intercultural em EA. Quando nos dispomos a estabelecer espaços educativos curriculares que possibilitem o estabelecimento de conversações (MATURANA, 1998) estamos valorizando uma relação de acolhimento, de cuidado, de reconhecimento do outro, enfim, de amorosidade que facilita, em muito, o rompimento com os silêncios impostos, historicamente, pelos processos de colonialismo autoritário e excludente. Tais práticas encontram, nos modelos de currículos tradicionais um lugar muito propício para se manterem e, o que é ainda pior, até prosperarem. Não raro as práticas educativas, em EA, não conseguem escapar dessa armadilha.

Em tais modelos curriculares encontram-se conteúdos os mais diversos e, o que é fundamental entendermos: sempre muito bem organizados. No entanto, se olharmos, atentamente, perceberemos que é uma organização decorrente de uma lógica política que privilegia certo tipo de conhecimento em detrimento de outro e uma concepção epistemológica alicerçada em pressupostos que absolutizam a razão em detrimento da emoção. Ao refletir sobre esta lógica política de organização da sociedade moderna, é importante o alerta de Boaventura Santos (2000), para quem, frente aos dois tipos de conhecimento presentes na modernidade (1) o conhecimento-regulação e (2) o conhecimento-emancipação, a opção foi pelo primeiro em detrimento do segundo. Desta opção decorre grande parte das práticas educativas e organizativas de nossa sociedade. Nossas orientações e diretrizes curriculares não escapam a essa tendência.

Uma demonstração desta desconsideração e, mesmo desprezo pelo conhecimento dos povos nativos ou mesmo de outras culturas e formas de viver em sociedade, é a frequência com que escutamos a afirmação de que vivemos, hoje, a era do conhecimento. Como se fosse possível existir alguma sociedade humana que não tivesse, de forma intrínseca no "fluir de seu viver" (MATURANA, 1998) suas dimensões inseparáveis: a dimensão da cultura e a dimensão da biologia. Ainda sobre a expressão "sociedade do conhecimento" é importante o que nos diz o ecologista e educador Porto-Gonçalves em seu livro A Globalização da natureza e a natureza da globalização, para ele esta expressão é,

No mínimo, infeliz, posto que uma sociedade sem conhecimento é, mesmo, uma impossibilidade lógica, biológica e histórica. Afirmar que o conhecimento tem um papel mais importante nos dias que correm do que em outro período qualquer, é (1) ignorar que o conhecimento está inscrito na vida, e (2) é levar longe demais a distinção trabalho manual e trabalho intelectual, na medida em que o que observamos hoje é que um modo de produção de conhecimento que está se impondo a todos sob controle de alguns (os grandes laboratórios de pesquisa das grandes corporações transnacionais com o apoio do Estado dos países do centro hegemônico do padrão de poder mundial)...todavia a diversidade de culturas da humanidade é a melhor expressão da diversidade de conhecimento" ( GONÇALVES, 2006, p.117-118).

Passando da lógica política hegemônica e olhando para a questão epistemológica, perceberemos que esta opção pela razão, como determinante de nossas práticas organizativas sociais, constatará que fomos "treinados" desde a mais tenra infância a acreditar que somos o que somos por sermos seres racionais. $\mathrm{E}$ sobre este aspecto são fundamentais as contribuições dos estudos e das pesquisas sobre a BA e BC de Maturana. Para o autor, ao nos denominarmos seres racionais estamos anunciando que "vivemos uma cultura que desvaloriza as emoções, e não vemos o entrelaçamento cotidiano entre razão e emoção, que constitui nosso viver humano, e não nos damos conta de que todo sistema racional tem um fundamento emocional" (MATURANA, 1998, p.15). 
Doi: $10.22478 /$ ufpb.1983-1579.2018v3n11.42394

http://periodicos.ufpb.br/ojs2/index.php

Grande parte dos estudos e pesquisas sobre currículo têm demonstrado a força e a importância que determinadas diretrizes acabam imprimindo nas relações didáticas, pedagógicas, metodológicas e organizativas dos espaços educativos escolares. Ao pesquisar as redes de relações que se estabelecem nos diferentes espaços e tempos da escola, Ferraço (2002) aposta no diálogo com as manifestações cotidianas de solidariedade e de companheirismo, estabelecidas entre os educandos, como caminho para a criação de alternativas de organização escolar e curricular, onde sejam privilegiadas atitudes que ajudem a romper com as práticas "individualistas e egoístas" que emergem das intrincadas e complexas redes de poder que circulam pelos currículos escolares tradicionais. Ao contrário destas redes de poder, que visam reafirmar uma cultura da dominação (MATURANA; XIMENA, 2005), Ferraço (2002) propõe que olhemos com muita atenção para as relações cotidianas que os educandos estabelecem entre si nos mais diferentes momentos. A reflexão trazida por Ferraço, só reafirma o fato de que a educação escolar não escapou deste processo de construção de uma cultura de dominação. Grande parte dos estudos e das pesquisas, sobre currículo, já demonstraram que as diretrizes e as práticas curriculares escolares acabam, ao fim e ao cabo, reproduzindo, como um espelho da sociedade e de seus modelos organizativos políticos e econômicos, enfim, culturais. Ou seja, se vivemos numa sociedade que incentiva relações de competição; que promove ações de aniquilamentos culturais; gestos de intolerâncias; atitudes que levam a degradações e poluições ambientais, mentais e sociais (GUATTARI, 1991), nada mais "natural" que termos práticas curriculares que ajudem a construção e consolidação deste processo.

\section{CURRÍCULO, TEMPO, ESPAÇO E EXPERIÊNCIA: como fica a educação ambiental?}

Queremos finalizar este item sobre currículo com algumas reflexões sobre o tempo e o espaço da escola. Isto em função de que as ideias que orientaram este texto atribuem uma importância fundamental para aquilo que nos acontece cotidianamente. Para Maturana (2004) o fluir de nosso viver resulta do entrelaçamento de nossa cultura com nossa biologia e, assim sendo, "nada pode acontecer comigo sem acontecer com minha biologia" (MATURANA, 2001, p.56). Uma biologia intrinsecamente acoplada com os processos de experienciação culturais vividos, pois "todos os domínios explicativos são domínios experienciais nos quais o observador vive novas experiências, faz novas perguntas, e, inevitavelmente, gera explicações de maneira incessante e recursiva" (MATURANA, 2001, p.134). Quando falamos de experiência significativa para a formação referimo-nos a algo semelhante ao que propõe Larrosa (2002) ao se referir à experiência e sentido. Para ele experiência não é a mesma coisa que informação. A experiência vista como "aquilo que nos toca". Cada vez mais somos bombardeados por uma gama de informações e eventos. Contudo, nem todas estas informações e/ou estes eventos tocam nossos sentidos.

A centralidade da reflexão neste texto se refere há um tempo e um espaço muito particular: o tempo e o espaço da escola. A escola como um lugar de palavras, gestos, silêncios, atitudes. Um lugar de experiências vivas e vividas. Lugar onde conhecimentos e saberes se encontram, se confrontam, se antropofagiam ou, se anulam. Tudo isto para lembrar que nada acontece fora do tempo. O tempo essa dimensão instituinte e instituidora de representações e imaginários sociais. O tempo numa perspectiva tomada de empréstimo de poetas como Jorge Luis Borges, que diz que dele somos feitos. Dele somos mais prisioneiros que senhores. Em tal representação, o tempo deixa de ser uma abstração, uma marcação cronológica ou biológica e se transforma na substância mesma da qual somos feitos. É tomando a experiência como um processo que acontece num espaço-tempo vivido, como uma forma de dizer de si e do mundo, que acreditamos na sua grande potência criativa para a construção de conhecimentos e saberes em relação à atuação docente. Mais ainda, refletindo sobre quais conhecimentos e/ou saberes deveriam compor o repertório curricular de educadores(as) para dar conta, minimamente, das questões de nossa época. Afinal, que exigências estão colocadas para a ação docente que leve ao desenvolvimento daquilo que Lüdke (2001, p.07) denomina de uma "prática docente efetiva" no cotidiano escolar? Referimo-nos a uma escola, a um espaço educativo para as pessoas que nela chegam que, como já defendia Freire nos idos da década de 70 do século passado, em Pedagogia do Oprimido (1970), pense os seres humanos como seres inconclusos. Com esta ideia freireana fazemos uma aproximação final com as ideais de Humberto Maturana quando este 
propõe a radicalidade da cooperação em substituição à competição. Foi à cooperação que nos proporcionou existir como espécie e não a competição. Por que, então, não pensar uma alternativa curricular em geral, e em EA em especial, que tenha como ponto de partida o amor como o princípio epistemológico e pedagógico? Tentamos mostrar nessa fase do texto, através do diálogo com algumas ideias de Maturana, que isto não só é possível como se torna cada vez mais urgente. Afinal, vivemos tempos difíceis. E difíceis, justamente, em decorrência das opções que até agora foram feitas por nós homens e mulheres em geral, e, educadores (as) em particular. A competição está presente em todos os atos de violência que acontecem. Na escola não é diferente. Já a cooperação aparece sempre que queremos dialogar, conversar, acolher, enfim, sempre que queremos buscar aliados para a edificação de um mundo social e ecologicamente mais justo.

\section{INTERCULTURA E ANTROPOFAGIA - uma educação ambiental nos trópicos}

Acreditamos que uma boa maneira de começarmos um texto sobre a EA, em um país como o Brasil, é lembrando que quando aqui chegaram os portugueses, nos idos de 1500, este território era habitado por cerca de mil povos. Eram os nativos que foram chamados de "índios" pelos portugueses. Viviam livres, alegres e "soltamente" como gostava de dizer Darcy Ribeiro (1922-1997). Hoje, transcorridos cerca de 500 anos, restam não mais de 225 destes povos habitando estas terras brasilis. Paradoxalmente, grande parte dos brasileiros não sabe que no seu país ainda existem 225 povos, além, é claro, da civilização branca ocidental. Não sabem, também, que ainda são faladas cerca de 360 línguas diferentes por estes povos. Infelizmente, mesmo nos meios acadêmicos e intelectuais poucos são os que sabem da existência deste ainda significativo contingente de brasileiros(as) nativos da terra de pindorama.

Se olharmos para nosso passado recente - últimos 500 anos - veremos que cerca de 800 povos foram de diferentes formas, dizimados. Com eles desapareceram suas línguas, seus rituais, seus hábitos alimentares, enfim, quando some uma língua, some com ela uma cultura. Portanto, quando desaparece um povo com estas características é aniquilada uma civilização inteira. Desaparece sua arte, sua filosofia. Sim, pois, estas civilizações possuíam um sistema filosófico de vida extremamente complexo e rico em contribuições para as demais formas de pensar a vida no planeta. Tanto isto é verdadeiro que são inúmeros os casos em que pesquisadores de vários países - e mesmo do Brasil - recorrem aos saberes dos povos nativos para estudarem, copiarem e transformarem em conhecimento científico e em mercadoria, aquilo que é um patrimônio de saberes milenares destes povos.

A intenção principal deste artigo sobre currículo e EA é propor uma ação pedagógica intercultural, orientada por uma concepção curricular em EA, que valorize os conhecimentos científicos sem esquecer o papel fundamental, na formação das pessoas, dos saberes da experiência e da vivência. Uma EA que coloque em contato a cultura local e a global. Uma proposta educativa baseada nos princípios da valorização das relações e das interações no estudo das culturas - a interculturalidade (BATESON 1904-1980), e aliada à proposição de estudo das culturas do antropólogo cultural Cliford Geertz (1926-2006), para quem nunca devemos esquecer que toda cultura tem uma base que é local, pois, assim como a técnica da navegação, a perícia da jardinagem, a beleza da construção poética, as disciplinas do conhecimento científico, também decorrem de artesanatos que são locais. Tendo como ponto de partida estas palavras iniciais é que denominamos de uma Educação Ambiental nos Trópicos, esta proposta que apresentaremos, de forma sucinta, a partir deste momento. Uma EA que tem como co-inspiração local as proposições filosóficas e epistemológicas do Movimento Antropofágico Brasileiro ${ }^{6}$ e como interlocução global as ideias e proposições

\footnotetext{
${ }^{6}$ Sobre a origem do nome, Antropofágico a este movimento, o mesmo decorre de um quadro que a pintora Tarsila do Amaral deu como presente de aniversário, (11/01/1928), ao marido Oswald de Andrade, um dos fundadores do movimento e autor do Manifesto Antropófago. A pintura constava de uma figura humana um pouco "estranha". Tinha mãos e pés muito grandes em contraste com uma cabeça diminuta. A coloração de terra da figura contrastava com o azul do céu, o sol alaranjado e um cactus verdejante, ao fundo. Ao receber o quadro de presente Oswald não o entendendo, socorreu-se de seu amigo modernista Raul Bopp, que também ficou intrigado com "aquilo" que Tarsila tinha pintado. A própria Tarsila chegou a perguntar: "Mas como é que eu fiz isso?" ao contemplar sua obra. Como brincadeira Oswald sugeriu que dessem à figura o apelido de um selvagem gigante. Recorreram ao dicionário de língua Tupi. Lá encontraram como sinônimo de Homem: Aba. Para aquele
} 
Doi: $10.22478 /$ ufpb.1983-1579.2018v3n11.42394

http://periodicos.ufpb.br/ojs2/index.php

de pensadores de diferentes épocas, lugares e áreas do conhecimento. É deste diálogo entre o local e o global, formadores das culturas, que poderemos edificar uma alternativa pedagógica e curricular em EA que contemple a diversidade cultural e que possa, assim, se inscrever numa perspectiva intercultural de educação e de currículo. Pensar uma EA nos Trópicos, numa perspectiva intercultural de educação, é buscar modos de exercê-la por meio dos entre-lugares resultantes dos entrecruzamentos que são produzidos e que nos chegam dos países considerados, tradicionalmente, como hegemônicos. Portanto, esta proposta pedagógica de EA se auto-declara (1) herdeira teórica das ideias e proposições filosóficas e epistemológicas da Antropofagia Cultural Brasileira e (2) se coloca em acordo com as ações e intervenções deste movimento cultural que, como muito oportunamente, o ecologista e educador Marcos Reigota define em sue livro Da Floresta à Escola - por uma educação ambiental pós-moderna, como o movimento inaugurador da pósmodernidade na Terra de Pindorama7.

\section{DA CÓPIA À INVENÇÃO - chega de sedentarismo intelectual}

O que estamos propondo como uma EA nos Trópicos, não é a defesa de mais um resgate, de uma releitura, nem mesmo uma recriação de algo do passado. Entendemos que muitas destas tentativas de releituras e de retomadas mais têm servido como uma busca de refúgio no sentido de manutenção de uma "zona de conforto intelectual" que uma tentativa real de superação de nossas fragilidades frente aos desafios educacionais contemporâneos. Esta EA nos Trópicos propõe alternativas a partir da relação de interação devorativa daquilo que nos chega e nos atravessa das demais culturas com as quais nos encontramos. Esta relação de tipo devorativa aceita a assimilação, assume o risco do jogo do deslizamento, da descentralização, da desconstrução. Enfim, não teme ser devorada no processo de devoração do outro, pois sabe, como bom antropófago que, mais cedo ou mais tarde, será vingada por um seu parceiro de tribo. Haverá sempre um parceiro mais forte e valente que devorará seu devorador, fazendo valer a lei oswaldiana do ritual antropofágico: "lei do homem, lei do antropófago" ou, simplesmente, Tupi or not Tupi, that is the question! Devorar ou ser devorado.

Este ritual de antropofagia pedagógica é que alimentará a EA nos Trópicos que estamos propondo a partir da Terra de Pindorama.

O descompasso da educação brasileira, em relação a outras áreas da produção de conhecimento no país, parece que assumiu a condição de "fato consumado". Passou a ser aceita como uma "coisa natural" nos espaços da vida cultural e social do país. Tem-se a sensação que isso não mais incomoda. As causas deste descompasso são muitas e contraditórias. Contudo, adiantamos que uma delas é o pouco caso que nossas elites intelectuais e políticas deram, historicamente, para as ideias de pensadores nacionais e mesmo para nossos vizinhos latino-americanos. Mesmo quando elaboramos nossas teses e demais trabalhos de pesquisas acadêmicas somos vitimados por essa estranha "mania" de ir buscar alhures às respostas para os problemas que nos desafiam. Não percebemos que, não raro, buscamos longe algo que pode estar muito próximo. Como ironizou Roberto Gomes, em Crítica da Razão Tupiniquim, ao alertar que temos uma imensa dificuldade em fazer o exercício, nada pequeno e fácil, de buscar ver aquilo que está "A um palmo diante de nosso nariz" (GOMES, 1986, p.18). Abrimos mão, assim, de exercer a coragem intelectual de começar a pensar por nossa própria conta e risco. Ao abdicar desta necessidade, fundamental para qualquer intelectual que mereça este nome, julgam alguns que serão finalmente aceitos. Abrem mão de sua palavra, de sua opinião, em nome da aceitação por parte daqueles que julgam ser seus "pares" e pertencentes a culturas mais "evoluídas ou adiantadas". Como se isso fosse possível de medir, de valorar. Gomes adverte: "Tendo se furtado a responder

que come carne humana: Poru. Foi fácil a ligação Aba-Poru. Aquele que come carne humana: Antropófago. Nasce assim a Antropofagia. (Fonte: Tarsila do Amaral. A modernista. São Paulo. SENAC, 1998).

${ }^{7}$ Pindorama - Que na língua Tupi-Guarani quer dizer terra das palmeiras. Essa era a denominação que os nativos que aqui os portugueses encontraram usavam para falar de sua terra. Era uma forma de demonstrar sua integração com a natureza da terra povoada de palmeiras. 
a urgências históricas nossas, a grande crise do intelectual tupiniquim é viver mendigando consideração e reconhecimento" (GOMES, p.51). Nesta caminhada de submissão e de colonialismo, o destino mais provável é a morte intelectual e a subserviência cultural.

Curiosa, ou tristemente, as elites brasileiras têm uma imensa dificuldade em olhar para elas mesmas e se reconhecerem. Parece padecerem de um sentimento de auto piedade, de uma baixa autoestima intelectual que as impede de assumir a condição de brasileiro e de cidadão latino-americano. Ao refletir sobre essa acomodação, frente à imposição de costumes e filosofias alienígenas, Antônio Candido (1973), em um artigo intitulado, Literatura e sub-desenvolvimento, alerta para a tendência que temos em aceitar isto como "natural" e inevitável. Para o autor uma prova incontestável disto é o fato desta questão nunca ter sido colocada para a discussão em nossas academias e rodas intelectuais. Para Clifford Geertz (2009), pioneiro nos estudos de interculturalidade, a cultura de um grupo social não é algo fácil de ser definido, delimitado e mesmo decifrado. Cultura é bem mais que uma relação de poder. É um emaranhado de signos e símbolos interculturais. Como alerta o antropólogo Roberto Da Matta (1978), nossas elites intelectuais se esmeraram em se fazer apartadas da sociedade em geral, para, com isto, poder falar por essa massa anônima chamada por elas de "povo". O autor resume sua preocupação numa pergunta: O que faz do Brasil, Brasil? O que faz da sociedade brasileira esse conjunto de gente tão cheia de generosidade, de sabedoria e, sobretudo, de esperança. Para ele, uma multidão privada de voz e de uma face própria, mas, que, paradoxalmente, tem uma elite já rouca de tanto reclamar por seus direitos e prerrogativas de uma intelectualidade sempre muito preocupada com as coisas do Brasil, mas, sempre tão voltada e presa ao "Último livro francês; uma criadagem que passa tão despercebida e patrões tão egocêntricos; uma sociedade, tão rica em leis e decretos racionais, mas que espera pelo seu D. Sebastião, o velho e ibérico pai de todos os renunciadores e messias" (DA MATTA, 1978, p.14). Enquanto isto, grandes pensadores brasileiros se destacavam aos olhos de seus colegas estrangeiros em diferentes áreas. Em nosso caso, na educação, o nome sempre lembrado fora do Brasil, é do educador do mundo Paulo Reglus Neves Freire (1921-1998). Um dos grandes pioneiros e exemplo de educador brasileiro que nunca deixou de dialogar com o mundo sem, contudo, descuidar de valorizar os saberes e os fazeres das gentes de sua terra.

Ao comentar essa curiosa situação, o educador popular Carlos Rodrigues Brandão faz um importante alerta e nos convida a pensar sobre se nossas teorias estão realmente nos ajudando no processo educativo. Ao refletir sobre certa proliferação excessiva de teorias e de sugestões de pedagogias em relação ao trabalho educativo, Brandão (2002, p.192) faz a seguinte provocação:

Há ideias demais sobre as crianças. Há um exagero de experiências por todo mundo, uma sobra de investigações a cada ano, algumas boas e úteis por muito tempo, e outras que afortunadamente envelhecem depressa. Há propostas de psicologias de pedagogias que sugerem "o que fazer com elas". Isto é necessário e quase sempre os estudos e as propostas são bem-vindas, mas a velocidade com que surgem e se repetem chega a ser assustadora. Menos para quem abriu mão de ler os livros com ideias inteiras e se contenta com resumos, resenhas e artigos de sete páginas nas viagens da internet.

Veja-se, portanto, que isto é uma prática antiga nos meios educacionais. Já na década de 70 do século passado, ao refletir sobre a formação cultural docente e suas carências, Brandão chamava a atenção para certo "apressamento" no encontro de soluções simples para problemas tão complexos quanto o de ensinar e aprender. Em um texto de 1972, intitulado Os abutres, o escritor Silviano Santiago, adverte sobre o atraso e o conservadorismo imperante na literatura brasileira, em relação às demais formas de produção artística no Brasil, usa uma expressão que pensamos se adequar muito bem para a situação que vivemos quatro décadas depois na educação. Escreve ele: "Perdemos o bonde, mas não percamos a esperança" (SANTIAGO, 1972, p.129). Não somos afeitos a posturas pessimistas e nem de saudosismos do tipo: no meu tempo a educação era melhor, antigamente os alunos estudavam mais e eram disciplinados, os professores eram respeitados, os mestres eram referências na sociedade, etc., etc. Contudo, tomar conhecimento do que está se passando 
Doi: 10.22478/ufpb.1983-1579.2018v3n11.42394

http://periodicos.ufpb.br/ojs2/index.php

com a educação brasileira é um primeiro passo no sentido de avançarmos do lugar em que nos encontramos. É quebrar a inércia a que estamos prisioneiros há décadas.

\section{PULANDO DE “GALHO EM GALHO” CURRICULAR OU... DEVORANDO A “ESTRANJA”}

É urgente devorar a “estranja” (Mário de Andrade).

Acreditamos que, em educação e em EA, a constatação de que não mais podemos continuar importando modelos e fórmulas, sem fazer a sua devida contextualização é o primeiro movimento no sentido de sairmos do cenário em que nos encontramos. Parece que nos especializamos na prática de ficar "pulando de galho em galho" quando se trata de pensar nossas alternativas pedagógicas e educativas. Somos muito pródigos em trocar - apressadamente - de uma teoria para outra, de um método para outro. Somos guiados pelos diferentes e rápidos modismos de além-mar. Adotamos, sem muita reflexão, os mais estapafúrdios modismos que chegam, e se dissolvem, cada vez com mais rapidez, via o grande bazar em que se transformou o meio midiático de circulação e consumo de informações. Isto ocorre na economia, na política, nas ciências sociais, e, como não poderia deixar de ser, na educação. Acabamos, nessa pressa consumista de teorias e modelos, adotando ideias e proposições que muito pouco, ou nada, tem a dizer aos nossos reais dilemas e desafios. Para Brandão (2001), esta mania de copiar e imitar ganhou, nos últimos tempos, um aliado poderosíssimo e muito competente: os meios midiáticos contemporâneos.

Ao propor uma EA nos Trópicos, reforçamos a necessidade de sairmos deste processo de cópia, de imitação e de posturas, por vezes, exageradamente conciliadoras para com as ideias. Em especial com as ideias alienígenas que nos chegam aos borbotões e são imediatamente "assimiladas" sem que passem por um profundo e criterioso processo de reflexão, de crítica, enfim, que sofram a devida devoração antropofágica e cultural. Esta devoração que propomos tem como principal objetivo não tomar-se as ideias como algo que exista em si e por si. Ao não aceitar essa assimilação pura e simples, estaremos abrindo espaço para que se construa um pouco de originalidade em nossa ação pedagógica educativa. Ao devorar criticamente as ideias e proposições que nos chegam estaremos reafirmando, concreta e efetivamente, a necessidade de romper com o pensamento colonizado e subalterno que se contenta em ser um mero "assimilador" daquilo que é oferecido pelo colonizador. Tal prática tem nos levado, década após década, a aceitação tácita de nossa condição de dependência e de submissão intelectual. Esta postura intelectual, pouco criativa e sedentária não nos permite perceber uma obviedade: o fato de algo que é muito importante para uma dada sociedade ou para uma determinada cultura, pode não ter relevância alguma para outra. Não passando de um mero adereço decorativo. Um mero "penduricalho". Uma das consequências imediatas, e extremamente prejudicial, desta postura de cópia, de imitação e de assimilação descontextualizada, é a busca de legitimação de nossas ideias e ações por meio da assunção de um pensamento de colonizado.

Em função disto, raramente temos, entre nós, uma busca criativa a partir de interlocução com os movimentos culturais das gentes da terra na perspectiva de valorização dos processos interculturais de diálogo e de aprendizagem. Ao buscar, a qualquer preço, a aceitação de parte da intelectualidade estrangeira, esquecemos quem somos e como nos constituímos sociologicamente em uma nação. Contentamo-nos em parecermos, ao contrário de buscar entender o que realmente somos. Para alcançar a aceitação e o reconhecimento das elites "de cima" e de outros centros considerados "mais evoluídos" são feitos verdadeiros malabarismos de conciliação intelectual. Não raro, esta conciliação aparece revestida de uma capa de dissimulação chamada de polimento, bom senso político, elegância acadêmica, ponderação, sensatez e outros eufemismos de pensamento das elites locais portadoras de uma mentalidade colonizada. A esta prática, decorrente de um servilismo filosófico, Roberto Gomes (1986), denomina de "pensamento ornamental”. Sérgio Buarque de Holanda alerta em Raízes do Brasil, que é muito frequente, os intelectuais brasileiros alimentarem-se, simultaneamente, de ideias e de filosofias de origens e orientações as mais diversificadas, bastando, para isto, que essas ideias, 
Se possam impor à imaginação por uma roupagem vistosa: palavras bonitas ou argumentos sedutores. A contradição que porventura possa existir entre elas parece-lhes tão pouco chocante, que alguns se alarmariam e se revoltariam sinceramente quando não achássemos legítima sua capacidade de aceitá-las com o mesmo entusiasmo. Não há, talvez, nenhum exagero em dizer-se que quase todos os nossos homens de grande talento são um pouco dessa espécie (HOLANDA, 2006, p.169).

Ao propormos uma EA nos Trópicos, tendo como uma de suas referências importantes para interlocução a Antropofagia Cultural Brasileira, queremos mostrar a atualidade deste movimento pósSemana de Arte Moderna de 1922. Tal movimento caracterizou-se por um radical questionamento e uma rejeição as hierarquias culturais que eram então uma norma imposta pelo Império português-europeu e de certa forma aceita, comodamente, pelas elites locais colonizadas e dóceis. Elites, essas, sedentas por receber, como prêmio de sua obediência, algumas migalhas do Império. Em contraponto a essa postura de servilismo das elites, os antropofágicos culturais, pós-Semana de Arte Moderna, ofereciam a experimentação e a participação do nativo e de suas formas de viver e de produzir existência como o centro gerador e inspirador de grande parte de suas produções artísticas.

Consideramos muito atual e pertinente às proposições do movimento antropófago de 1922. Nunca se viveu um tempo onde à crise do multiculturalismo, de vertente europeia, passasse por tão grave questionamento. A antropofagia Cultural tem a oferecer um contraponto às oposições de tipo binárias, do isto ou aquilo; da fixação do interior e exterior; do próprio e do outro; de centro e de periferia; de noções de desenvolvimento e subdesenvolvimento; do individual e do coletivo; do antagonismo simplista entre nativo e estrangeiro. A estas posturas fixas e reducionistas, que caracterizaram certo ideário moderno e conservador, a Antropofagia Cultural propõe a mestiçagem, a mistura e a miscigenação. Algo na perspectiva defendida, para a produção artística pelo antropofágico e artista plástico Hélio Oiticica (1937-1980), para quem, para se conhecer o Brasil é preciso começar a transpor as fronteiras culturais que acabam por nos impedir de ver:

“como é o Brasil" no mundo, ou como ele "é realmente" - dizem: estamos sendo invadidos por uma cultura estrangeira - dizem: ou por hábitos estranhos, música estranha, etc.; como se isso fosse um pecado ou uma culpa - o fenômeno é borrado por um julgamento ridículo, moralista-culposo: "não devemos abrir as pernas à cópula mundial - somos puros" - esse pensamento, de todo inócuo, é o mais paternalista e reacionário atualmente aqui. Uma desculpa para parar, para defenderse - olha-se demais para trás - tem-se saudosismo às pampas - todos agem um pouco como viúvas portuguesas: sempre de luto, carpindo (OITICICA, 2009, p.114).

Nada mais antropofágico e oswaldiano que isto. Uma verdadeira homenagem, um tributo aos Tupinambás antropófagos, devoradores de bispos e outros valentes inspiradores dos antropofágicos Póssemana de Arte Moderna de 1922. Agindo desta forma estaríamos dando um passo importante na direção do que alguns autores estudiosos das relações interculturais denominam de hibridação cultural (CANCLINI, 2006; 2003; BHABHA, 2003; FLEURI, 2003; 2009). Poucos países tem em sua formação étnica e cultural uma gama tão ampla de diversidades como o Brasil. Somos uma terra de múltiplas facetas culturais que geram diferenças que se fundem e confundem na prática cotidiana do viver. Como em raros outros lugares do mundo a pureza e a originalidade não se fazem presentes como artefato cultural identitário como na terra brasilis. Ao se referir a esta característica de hibridação, Silviano Santiago afirma que uma das grandes contribuições da América Latina para a cultura do mundo ocidental é a demonstração, na prática do viver, da destruição da ideia de unidade e de pureza de culturas. O autor cita como exemplo o que já escrevia em 1945, Oswald de Andrade, em seu livro Ponta de Lança (1972, p.62): "A Alemanha racista e recordista precisa ser educada pelo nosso mulato, pelo chinês, pelo índio mais atrasado do Peru ou do México, pelo africano do Sudão. É preciso ser misturada de uma vez para sempre. Precisa ser desfeita no melting pot do futuro. Precisa mulatizar-se". Oswald segue adiante ao escrever "nada podemos esperar da Europa europeia, para onde 
Doi: $10.22478 /$ ufpb.1983-1579.2018v3n11.42394

http://periodicos.ufpb.br/ojs2/index.php

vivemos por tanto tempo voltados, com a luz de Paris em nossos espíritos. Foi uma época que terminou" (ANDRADE, 1945, p.63). Para Eduardo Viveiro de Castro, temos uma visão ainda muito dogmática e mesmo retrógrada sobre o que é uma cultura e como ela pode ir se constituindo ao longo do processo de viver dos povos. Comportamo-nos como se estivéssemos em busca de um elo perdido, de uma essência, de uma raiz única para cada cultura. Para Castro (2008, p.149),

Não há culturas inautênticas, pois não há culturas autênticas. Não há, aliás, índios autênticos. Índios, brancos, afrodescendentes, ou quem quer que seja - pois autêntico não é uma coisa que os humanos sejam. Talvez seja uma coisa que só os brancos podem ser (pior para eles). "A autenticidade é uma invenção da metafísica ocidental, ou mais que isso, ela é o seu fundamento"

Para o escritor Silviano Santiago (2006, p.35) estes conceitos de pureza e de unidade "Perdem seu contorno, perdem seu peso esmagador, seu sinal de superioridade cultural, à medida que o trabalho de contaminação latino-americano se afirma, se mostra mais e mais eficaz". Para este autor, a América Latina ocupa seu lugar no mapa do mundo e da civilização do ocidente em função deste movimento de desvio, de deslizamento, como forma de resistir e/ou contornar a norma, a disciplina impositiva e os costumes estranhos aos povos da América em geral e do Brasil em particular. Dentre os países latino-americanos, o Brasil, se constitui, a nosso ver, no exemplo desta capacidade de desconstituir esta proposição sociológica e antropológica de pureza e de unidade cultural plena, muito ao gosto do pensamento antropológico e sociológico europeu moderno. Não por acaso, já nos seus Manifestos Pau-Brasil (1924) e Antropófago, (1928), Oswald de Andrade bradava: "Nunca fomos catequizados" e "Antes dos portugueses descobrirem o Brasil já tínhamos descoberto a felicidade”. Uma comprovação desta possibilidade de resistência é o fato histórico, facilmente comprovado, da crueldade com que os conquistadores tiveram de se valer para impor sua hegemonia de imperialismo cultural. Seguindo essa mesma perspectiva de reflexão, Holanda (1902-1982) em seu livro clássico Raízes do Brasil, adverte para as consequências da tentativa de implantação em terras distantes de uma cultura europeia de tradição tão estranha à civilização milenar aqui existente. Este é, talvez, o fato mais relevante a ser levado em conta quando queremos entender a sociedade brasileira. Ao trazer de países tão distantes novas formas de convivência, novas instituições, ideias alienígenas, e insistindo em manter e implantar tudo isto num território simbólico, via de regra hostil, acaba por nos fazer, ainda nos dias atuais, como que desterrados em nossa própria terra. Estrangeiros em seu próprio país. Na opinião de Holanda (2006), se podemos projetar e construir obras maravilhosas e contribuir para a cultura da humanidade com aspectos novos e imprevistos e, ao mesmo tempo elevar à perfeição o modelo de civilização que representamos, cabe então perguntar: seria certo pensar que todo nosso trabalho de construção cultural decorreria de um sistema de evolução proveniente de outro continente, de outra cultura, enfim, de algo totalmente fora de nossa experiência vivida e que, ao fim e ao cabo, pode abrir mão de toda sua contribuição de origem?

Ao estudar as origens da formação da nação brasileira, Ribeiro vai buscar nas artes e nas técnicas dos povos nativos exemplos de como era diversificada e sofisticada a vida destes povos. Só para citar um exemplo na arte e outro nas técnicas produzidas e utilizadas pelos tupis-guaranis, o autor cita a criatividade dos indígenas, presente em tudo o que eles produziam. Seja num artefato para a guerra, num equipamento para a caça ou a pesca, seja num objeto para o uso doméstico. A preocupação com a beleza se faz integrante o tempo todo. Assim se refere,

Na vida indígena o que se vê nas coisas mais simples é esta alegria de viver, esta vontade de beleza expressa de mil modos, por gente comum, que tem um contentamento que entre nós só é dado ao artista criador ou ao apreciador mais sofisticado das nossas altas artes inacessível ao homem comum. Lá, a criatividade está generalizada. É impensável deixar de ver a perfeição formal de uma panela, de uma peneira, de uma casa ou de um colar. Um corpo pintado com urucum para uma 
tarde de festa é uma obra de arte feita com o zelo com que um pintor pinta uma tela. Uma perfeição perfeitamente inútil se poderia dizer. Mas a beleza á precisamente isso, é uma perfeição perfeitamente inútil que esquenta o coração e dá alegria. (RIBEIRO, 2008, p.67).

Mas não é apenas nas artes que as civilizações dos trópicos se destacaram e deixaram grandes legados. Na técnica, também, foram criativos e sofisticados. É o caso das técnicas de domesticação de plantas selvagens que desenvolveram e com as quais acrescentavam uma dieta rica e farta à sua subsistência. É da responsabilidade dos nativos a introdução nos hábitos alimentares brasileiros da mandioca, do amendoim, do abacaxi, da batata chamada de "batata inglesa", do milho, da batata doce, do inhame e muitas outras espécies que até os dias de hoje fazem parte de nosso cardápio rotineiro. Ribeiro ressalta, que com toda nossa sofisticada tecnologia ainda não domesticamos nenhuma outra planta além daquelas que os nativos deixaram para nós. Ao analisar as contribuições da Antropofagia Cultural Brasileira e do pensamento oswaldiano nas artes em geral e na literatura em particular, Silviano Santiago, (2006), salienta a forma como o antropofágico Oswald de Andrade recupera o que de forma injusta tem sido tomado por grande parte dos sociólogos e mesmo dos historiadores, que veem o passado brasileiro como algo totalmente desprovido de contribuição cultural. Esta historiografia oficial e elitista, com sua visão de intelectual preguiçoso e colonizado, não é capaz de perceber e reconhecer, este passado cultural como algo a ser levado em consideração. Para Santiago,

A possível contribuição cultural das raças indígenas no diálogo com a Modernidade ocidental. Este reducionismo acaba por valorizar uma razão etnocêntrica, intolerante, incapaz de manter diálogo com o seu outro (as culturas ameríndias e africanas), pois sempre coloca em situação hierarquicamente desfavorável e como responsável pelas piores "contaminações que a "pureza” ocidental pode sofrer". Esse reducionismo, em geral, rechaça o saber antropológico, pois desqualifica como equívoco ufanista qualquer contribuição que possa advir daquele conhecimento, negando a ele a condição de parceiro num frutífero diálogo seu com a história (SANTIAGO, 2006, p.137).

Ao analisar o processo histórico-cultural da sociedade brasileira percebe-se, facilmente, a busca de um distanciamento das elites em relação ao seu mundo próximo. Nota-se como que uma espécie de desapego intencional a tudo que acontece a sua volta. Tal postura é sacramentada através de uma relação de cópia e de imitação dos ideais de uma Europa idealizada. A mesma Europa que Andrade chamou de uma civilização que já se mostrava "cansada e triste". Ao fazermos essa crítica ao hábito de copiar e de imitar modelos estranhos, ressalte-se que esses modelos são estranhos a grande parte da população brasileira. Já, para as elites econômicas e políticas, tais modelos serviam muito bem aos seus interesses de exploração. Portanto, o que se percebe é que as elites nacionais são, em verdade, um ponto de apoio, um setor intermediário e intermediador das elites hegemônicas mundiais de então. Nesta mesma perspectiva de pensamento, o educador Paulo Freire, nosso raro, senão único, exemplo de exercício antropofágico na educação brasileira, nunca cansava de ensinar que o que aconteceu na América não foi descobrimento, mas, sim, conquista. Freire assim se manifesta:

A presença predatória do colonizador, seu incontido gosto de sobrepor-se, não apenas ao espaço físico, mas ao histórico e cultural dos invadidos, seu mandonismo, seu poder avassalador sobre as terras e as gentes, sua incontida ambição de destruir a identidade cultural dos nacionais, considerados inferiores, quase bichos, nada disto pode ser esquecido quando, distanciados no tempo, corremos o risco de "amaciar" a invasão e vê-la como uma espécie de presente "civilizatório" do chamado Velho Mundo (FREIRE, 2000, p.74).

Andrade, em seu modo sarcástico de dirigir sua crítica às elites nacionais, o não as poupa em suas arrogâncias caricaturizando-as no seu Manifesto Antropófago (1928) como "Elites vegetais em contato direto 
Doi: $10.22478 /$ ufpb.1983-1579.2018v3n11.42394

http://periodicos.ufpb.br/ojs2/index.php

com o solo". Já em Ponta de Lança, Andrade prossegue sua provocação ao ironizar a jactância doutoral das elites ao sugerir a Roberto Freyre que o mesmo proceda a uma curva clínica da palavra doutor entre nós, pois,

Acredito que a disseminação desse qualificativo honorífico é filha de uma compensação urgida pelo nosso analfabetismo. Primeiro, só os médicos eram doutores, depois os bacharéis se apossaram do distintivo, com desespero dos que colavam grau em borla e capelo. Qualquer pândego espirrava da Academia com dez anos de "simplesmente grau 1" e era doutor. Em seguida os farmacêuticos viraram doutores, os dentistas também, enfim os banqueiros, os ferragistas os leiloeiros. $\mathrm{E}$ os médicos, para não se confundir, chamaram-se professores, o que antes só indicava a modesta função de mestre-escola" (ANDRADE, 1972, p.60).

São reflexões deste tipo que nos impulsionam na direção de diálogos com outros referenciais teóricos que não apenas aqueles que buscam entender nossas ideias e atitudes a partir de referências históricas e culturais trazidas pelos europeus aqui recém-chegados nos idos do "descobrimento". Descobrimento, que o estudioso das gentes do Brasil, Darcy Ribeiro (1922-1997), denominou de "achamento". Uma forma semelhante à buscada por Freire para dizer do encontro entre duas civilizações - americana e europeia - e não o encontro de uma civilização (a europeia) e de uma horda feita de bárbaros: os nativos da América.

\section{HÁ LUZ NO INÍCIO DO TÚNEL... OU DO CURRÍCULO}

Ao contrário de reafirmar, comodamente, clichês do tipo “Há luz no fim do túnel” preferimos a aposta na existência da luz no início do túnel. Basta que comecemos a olhar para o que está à nossa volta. Em educação e em EA isto não é diferente. O que defendemos, neste texto, foi o fato de que se quisermos, realmente, nos livrar do bolor acadêmico e intelectual que há séculos reveste nossas práticas pedagógicas e curriculares de EA devemos partir para a conquista de nossa alforria intelectual. Só a partir do momento em que nos propusermos a declarar essa independência é que começaremos, de fato, a tomar para nossa responsabilidade a construção de uma nação social e ecologicamente mais justa, e, em paz. Esta pedagogia para a EA brasileira, que denominamos de EA nos Trópicos, precisa se inventar a partir de um profundo mergulho na cultura, na vida, no cotidiano, enfim, deve brotar da multiplicidade intercultural em que se constitui aquilo que denominamos de "realidade brasileira".

Chegada à hora de dar uma pausa neste texto, queremos dizer que esta EA nos Trópicos não se realizará apenas com livros e textos. Certamente não se realizará se depender apenas de livros e de teses acadêmicas, por mais pertinentes e relevantes que sejam. Elas - as teses e os livros - são, sem sombra de dúvida, muito importantes e sempre bem vindas. Porém, não são suficientes. Acreditamos que sua realização e complementaridade depende, e muito, da reflexão que fizermos, bem como das ações que, a partir destas reflexões buscarmos implementar nos espaços educativos por meio de nossas práticas pedagógicas e diretrizes curriculares.

O que estamos fazendo, neste texto, é oferecer aos leitores(s) um projeto. Um desejo. Neste sentido, não está pronto, está por realizar-se. Encontra-se aberto para as contribuições de todos (as) aqueles (as), educadores(as), que ainda acreditam que outra EA é possível e que ela pode ter origem nos trópicos. Que acreditam que nós, educadores (as) e cidadãos do Brasil, temos, sim, algo a dizer. Estamos cientes de algumas coisas. Entre elas é a de que podemos não saber, exatamente, qual o caminho que nos levará a esta EA nos Trópicos. No entanto, já temos o mapa dos caminhos que não desejamos mais continuar percorrendo. Foi um pouco desse mapa que buscamos rascunhar e oferecer aos leitores (as).

O que estamos propondo é um diálogo devorativo e antropofágico com todos os "estrangeiros culturais" com os quais estamos, cada vez mais, condenados a nos encontrar neste mundo em que já estamos, para o bem e para o mal, todos juntos. Enfim, esta EA nos Trópicos carrega consigo um pouco de tudo aquilo que fomos, daquilo que somos e aposta, também, na realização dos sonhos daquilo que queremos ser. 


\section{REFERÊNCIAS}

ANDRADE, O. Ponta de Lança. Rio de janeiro. Civilização Brasileira, 1972.

ANDRADE. O. Do Pau-Brasil à antropofagia e às utopias. Obras Completas. V.6. Rio de Janeiro. Civilização Brasileira, 1970.

. Estética e Política. São Paulo, Globo, 1992.

BATESON, G. Mente e Natureza - a unidade necessária. Rio de Janeiro. Francisco Alves, 1986.

BARBOSA, I. O. Alternativas emancipatórias em currículo (Org.) São Paulo: Cortez, 2004.

BHABHA, H. O local da cultura. Belo Horizonte. Ed. UFMG, 2003.

BOAVENTURA SANTOS, S. A Crítica da Razão Indolente: contra o desperdício da experiência, v. 1. São Paulo. Cortez, 2000.

BRANDÃO, C. R. A educação como cultura. Campinas. Mercado Aberto, 2002.

CANCLINI. N.G. Consumidores e Cidadãos. Rio de Janeiro. UFRJ, 2006.

. Culturas Híbridas. São Paulo. EDUSP, 2003.

CANDIDO. A. Literatura e Sociedade. Estudos de teoria e história literária. São Paulo. T.A. QUEIRÓS, 2000.

CASTRO, E. V. De. Encontros. Rio de Janeiro. AZOUGUE, 2008.

DA MATTA, R. CARNAVAIS, MALANDROS E HERÓIS. Rio de Janeiro. ZAHAR EDITORES, 1979.

FERRAÇO, C. E. Redes entre saberes, espaços e tempos. In: ROSA, D.E.G; SOUZA. V.C. (Orgas.) Políticas Organizativas e curriculares, educação inclusive e formação de professores. Rio de Janeiro. DP\&A Editora, 2002.

FLEURI, R. M. Intercultura e Movimentos Sociais. Florianópolis. NUP-UFSC, 1998.

N.23, 2003.

. Intercultura e Educação. Revista Brasileira de Educação-ANPEd. Editores Associados, Campinas-SP.

FREIRE, P. Pedagogia da Autonomia. Rio de Janeiro. Paz e Terra, 1997.

, Pedagogia do Oprimido. Rio de Janeiro. PAZ e TERRA, 1970.

, Pedagogia da indignação. São Paulo. UNESP, 2000.

GEERTZ, C. O saber Local. VOZES, 2009.

GOMES, R. Crítica da Razão Tupiniquim. Criar. Curitiba, 1981.

GUATTARI, F. As Três Ecologias. São Paulo. Papirus, 1991.

HOLANDA, S. B. Raízes do Brasil. São Paulo. Companhia das Letras (Edição comemorativa aos 70 anos), 2006.

LARROSA, J. Literatura, experiência e formação. In: COSTA, M. V. Caminhos investigativos novos olhares na pesquisa em educação. Rio de Janeiro: DP\&A, 2002.

LÜDKE, M.. A complexa relação entre o professor e a pesquisa. En: ANDRÉ, M. E. D.

OITICICA, H. Encontros/Hélio Oiticica. Rio de Janeiro. Beco do Azougue, 2009.

MATURANA, H.R. La realidad: objetiva o construída? Fundamentos biológicos Del conocimiento. Barcelona, 1996.

MATURANA, H.; Reflexões sobre o amor. In:.MAGRO, C; GRACIANO,M; VAZ, N. (Orgs). A ontologia da realidade Belo Horizonte. UFMG, 1997.

. Emoções e linguagem na educação e na política. Belo Horizonte. UFMG, 1998. 
. A Ontologia da Realidade. Belo Horizonte. UFMG, 1997.

. Da biologia à psicologia. Porto Alegre. ARTES MÉDICAS, 1998.

MATURANA, R.M.; VERDEN-ZÖLLER,G. Amar e brincar - fundamentos esquecidos do humano. São Paulo. Palas Athena, 2004.

MATURANA, H.R.; VARELA, F. De máquinas e seres vivos - Autopoiese - a organização dos seres vivos. Porto Alegre. Artes Médicas, 1997.

. COGNIÇÃO, CIÊNCIA E VIDA COTIDIANA. Belo Horizonte. UFMG, 2001.

MATURANA, H. \& DAVILA, X. Educación desde la matriz biológica de la existencia humana: biología del conocer y biología del amar. Disponível em: www.matriztico.org, Chile: 2005. Último acesso: 22/08/2018.

MATURANA, H.; VERDEN-ZÖLLER, G. Amar e brincar: fundamentos esquecidos do humano do patriarcado à democracia. São Paulo, SP: Palas de Athenas, 2004.

MATURANA, H. R. \& VARELA, F. G. A árvore do conhecimento: as bases biológicas do conhecimento humano. Campinas, SP: Workshopsy, 1995.

MATURANA, H. R. Emoções e linguagem na educação e na política. Belo Horizonte, MG: UFMG, 1998.

PORTO-GONÇALVES, C.W. A Globalização da natureza e a natureza da globalização. Rio de Janeiro. Civilização Brasileira, 2006.

PAZ, O. Obras Completas. V. III. México. Fondo de Cultura Econômica, 1994. 13v.

REIGOTA, M. A Floresta e a Escola: por uma educação ambiental pós-moderna. São Paulo. Cortez, 1999.

- Trajetórias e Narrativas através da educação ambiental. RJ. DP\&A Editora, 2003.

RIBEIRO, D. O povo brasileiro - a formação e o sentido do Brasil. São Paulo. Companhia das Letras, 1996.

RIBEIRO, D. Utopia Brasil. São Paulo. HEDRA, 2008.

RIBEIRO, D. Encontros. Rio de Janeiro. Beco do AZOUGUE Editorial, 2008.

SANTIAGO, S. Ora (direis) puxar conversa - ensaios literários. Belo Horizonte. Ed. UFMG, 2006. . S. Uma Literatura nos Trópicos. Rio de Janeiro. ROCCO. $2^{\text {a }}$. Ed. 2000. 